\title{
Case Report \\ Cerebral Arterial Air Embolism Associated with Mechanical Ventilation and Deep Tracheal Aspiration
}

\author{
S. Gursoy, C. Duger, K. Kaygusuz, I. Ozdemir Kol, B. Gurelik, and C. Mimaroglu \\ Department of Anesthesiology, School of Medicine, Cumhuriyet University, 58140 Sivas, Turkey \\ Correspondence should be addressed to C. Duger, cevdetduger@gmail.com
}

Received 2 April 2012; Accepted 27 June 2012

Academic Editors: A. X. Freire and K. Watanabe

Copyright () 2012 S. Gursoy et al. This is an open access article distributed under the Creative Commons Attribution License, which permits unrestricted use, distribution, and reproduction in any medium, provided the original work is properly cited.

\begin{abstract}
Arterial air embolism associated with pulmonary barotrauma has been considered a rare but a well-known complication of mechanical ventilation. A 65-year-old man, who had subarachnoid hemorrhage with Glasgow coma scale of 8 , was admitted to intensive care unit and ventilated with the help of mechanical ventilator. Due to the excessive secretions, deep tracheal aspirations were made frequently. GCS decreased from 8-10 to $4-5$, and the patient was reevaluated with cranial CT scan. In CT scan, air embolism was detected in the cerebral arteries. The patient deteriorated and spontaneous respiratory activity lost just after the CT investigation. Thirty minutes later cardiac arrest appeared. Despite the resuscitation, the patient died. We suggest that pneumonia and frequent tracheal aspirations are predisposing factors for cerebral vascular air embolism.
\end{abstract}

\section{Introduction}

Embolism of air into the cerebral vessels is an iatrogenic complication of numerous invasive medical procedures performed in anesthesia and intensive care [1] and may occur either in artery or in vein if an entry in the arterial or venous circulation is created [2-6]. Arterial air embolism associated with pulmonary barotrauma has been considered a rare, but a well-known complication of mechanical ventilation [7]. The volume of intravascular air embolised in the cases is usually small. Massive air embolism to the major cerebral vessels is extremely rare. We report a patient with an unusual air collection at the cerebrum during positive pressure ventilation.

\section{Case}

A 65-year-old man known with long-lasting arterial hypertension arrived at the emergency department in a subcomatose state. Subarachnoid hemorrhage (SAH) was seen on $\mathrm{CT}$ scan of brain. When admitting to intensive care unit, Glasgow coma scale (GCS) of the patient was 8 and he had spontaneous but insufficient breathing. Thus he required intubation after 1 hour of ICU admission. The patient was ventilated by mechanical ventilator in spontaneous mode.
Four days after intubation the patient had excessive bronchial secretions and nosocomial pneumonia was diagnosed. Due to the excessive secretions, deep tracheal aspirations were made frequently. GCS was $8-10$, and he was breathing in spontaneous mode in mechanical ventilator. GCS decreased from $8-10$ to $4-5$, and the patient was reevaluated with cranial CT scan in the 8th day of admittance. In CT scan, air embolism was detected in the cerebral arteries (Figures 1 and 2). The patient deteriorated and lost spontaneous respiratory activity just after the $\mathrm{CT}$ investigation. The airway pressure increased and pulmonary compliance decreased. Arterial blood pressure and saturation of the arterial oxygen decreased and cyanosis appeared. Meanwhile, GCS was 3. Treatment was started for the air embolism but 30 minutes later cardiac arrest occurred. Despite the resuscitation, the patient died.

\section{Discussion}

Cerebral vascular air embolism may be seen either in artery or in vein [8]. Cerebral air embolism most commonly results from arterial air embolism [9]. On the other hand, retrograde rising of air bubbles in the venous system has been demonstrated in an experimental setting [10]. The complication of 


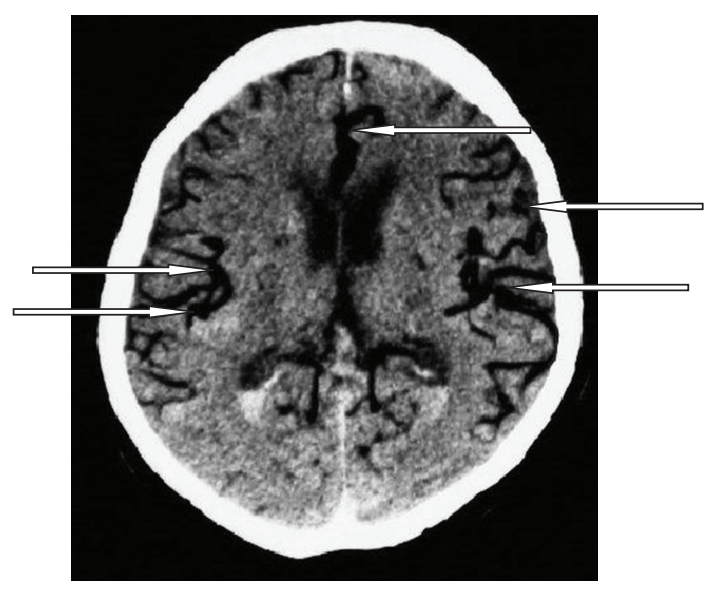

FIgURE 1: A section of cranial CT scan in the 8th day of admittance. Arrows show arterial air embolism.

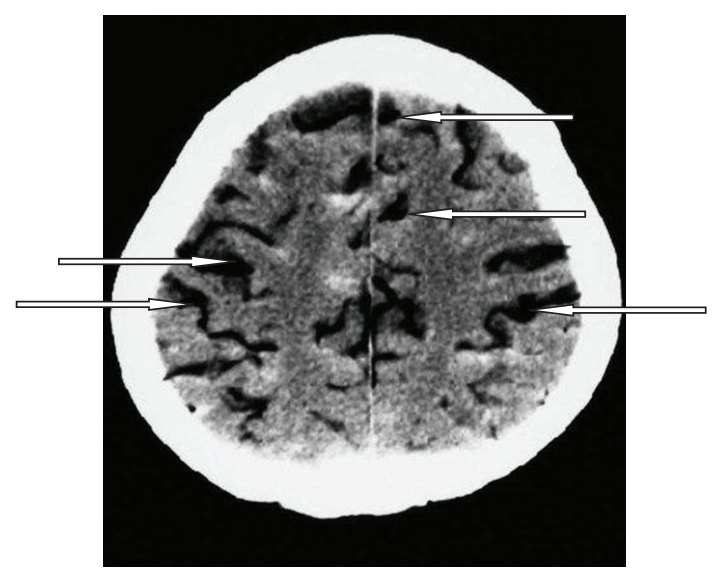

FIgURE 2: A section of cranial CT scan in the 8th day of admittance. Arrows show arterial air embolism.

cerebral vascular air embolism may result either severe neurological injury or death. The arterial embolism has higher mortality than the venous air embolism; the latter may has a good prognosis. The air may be absorbed spontaneously in venous embolisms. In mechanic ventilation with positive pressure, barotraumas may cause the air embolism $[8,11$, 12]. There is a predisposition for the mechanical ventilation induced air embolism, in the patients with thorax trauma, pneumothorax and bronchoscopy administration [11-13]. Symptoms vary with the location of the occlusion and the size of the air bubbles [10]. Hemoptysis and sudden cardiac and cerebral dysfunction of the mechanically ventilated patients should suggest the cerebral air embolism [14]. In our case, sudden cerebral dysfunction was observed. Continuous positive pressure ventilation was a predisposing factor for pulmonary infection and pulmonary infection induced excessive pulmonary secretions caused frequent tracheal aspirations.

In conclusion, we suggest that pneumonia and frequent tracheal aspirations are predisposing factors for cerebral vascular air embolism which should not be ignored in mechanically ventilated patients.

\section{References}

[1] C. M. Muth and E. S. Shank, "Gas embolism," New England Journal of Medicine, vol. 342, no. 7, pp. 476-482, 2000.

[2] C. B. Ordway, "Air embolus via CVP catheter without positive pressure: presentation of case and review," Annals of Surgery, vol. 179, no. 4, pp. 479-481, 1974.

[3] D. B. Price, P. Nardi, and J. Teitcher, "Venous air embolization as a complication of pressure injection of contrast media: CT findings," Journal of Computer Assisted Tomography, vol. 11, no. 2, pp. 294-295, 1987.

[4] D. Rubinstein and D. Symonds, "Gas in the cavernous sinus," American Journal of Neuroradiology, vol. 15, no. 3, pp. 561566, 1994.

[5] W. Takahashi, F. Yoshii, S. Ohsuga, Y. Izumi, and Y. Shinohara, "Two patients with paradoxical cerebral air embolism due to accidental disconnection of a subclavian intravenous catheter," Japanese Journal of Stroke, vol. 17, pp. 89-94, 1995.

[6] J. H. Wooding and A. M. Fried, "Nonfatal venous air embolism after contrast-enhanced CT," Radiology, vol. 167, no. 2, pp. 405-407, 1988.

[7] D. H. Park, Y. G. Chung, S. H. Kang, J. Y. Park, Y. K. Park, and H. K. Lee, "Arterial cerebral air embolism at the site of a spontaneous pontine hemorrhage in a patient receiving erroneous continuous positive pressure ventilation," Clinical Neurology and Neurosurgery, vol. 109, no. 9, pp. 803-805, 2007.

[8] L. K. Weaver and A. Morris, "Venous and arterial gas embolism associated with positive pressure ventilation," Chest, vol. 113, no. 4, pp. 1132-1134, 1998.

[9] M. C. A. Müller, S. M. Lagarde, M. R. Germans, and N. P. Juffermans, "Cerebral air embolism after arthrography of the ankle," Medical Science Monitor, vol. 16, no. 7, pp. 92-94, 2010.

[10] C. J. Schlimp, T. Loimer, M. Rieger, W. Lederer, and M. B. Schmidts, "The potential of venous air embolism ascending retrograde to the brain," Journal of Forensic Sciences, vol. 50, no. 4, pp. 906-909, 2005.

[11] J. J. Marini and B. H. Culver, "Systemic gas embolism complicating mechanical ventilation in the adult respiratory distress syndrome," Annals of Internal Medicine, vol. 110, no. 9, pp. 699-703, 1989.

[12] A. M. H. Ho, S. Lee, B. A. Tay, and D. C. Chung, "Lung isolation for the prevention of air embolism in penetrating lung trauma. A case report," Canadian Journal of Anesthesia, vol. 47, no. 12, pp. 1256-1258, 2000.

[13] S. C. Hung, H. C. Hsu, and S. C. Chang, "Cerebral air embolism complicating bilevel positive airway pressure therapy," European Respiratory Journal, vol. 12, no. 1, pp. 235-237, 1998.

[14] A. M. H. Ho and E. Ling, "Systemic air embolism after lung trauma," Anesthesiology, vol. 90, no. 2, pp. 564-575, 1999. 


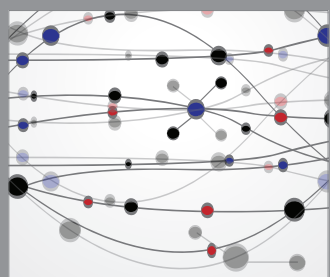

The Scientific World Journal
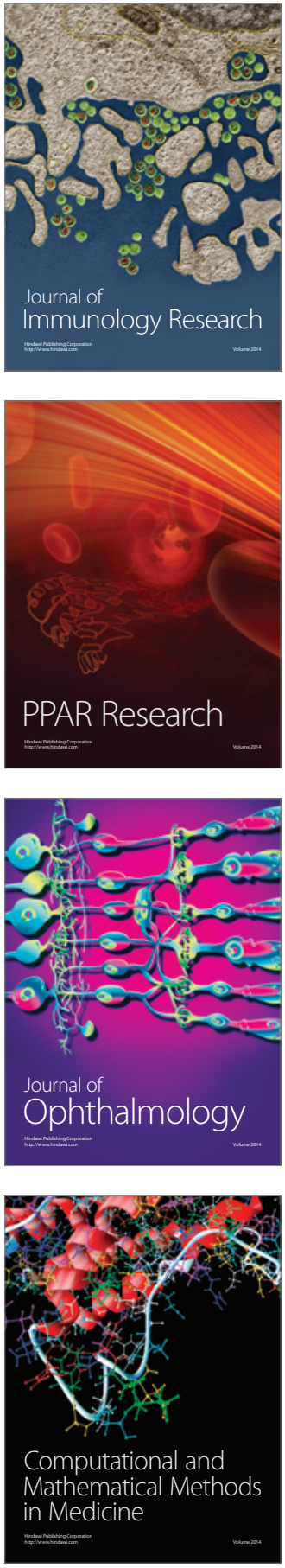

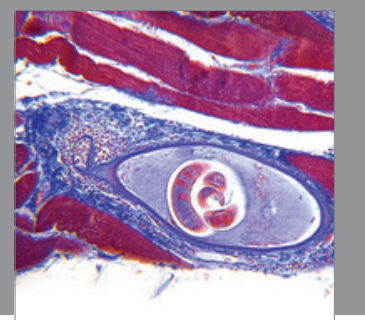

Gastroenterology

Research and Practice
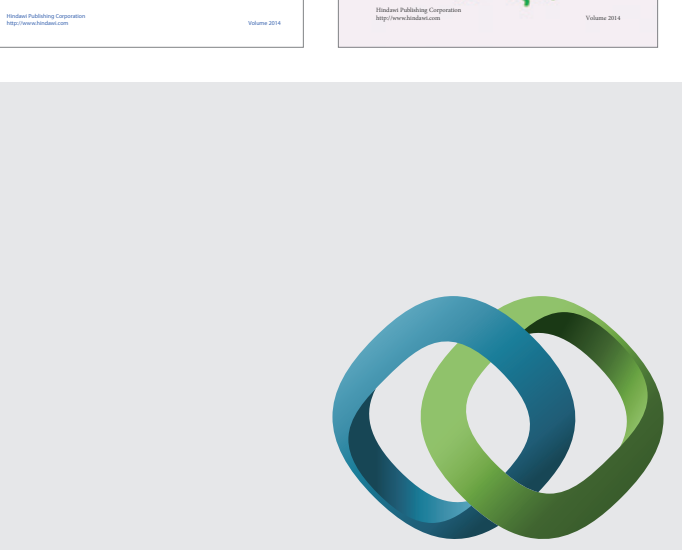

\section{Hindawi}

Submit your manuscripts at

http://www.hindawi.com
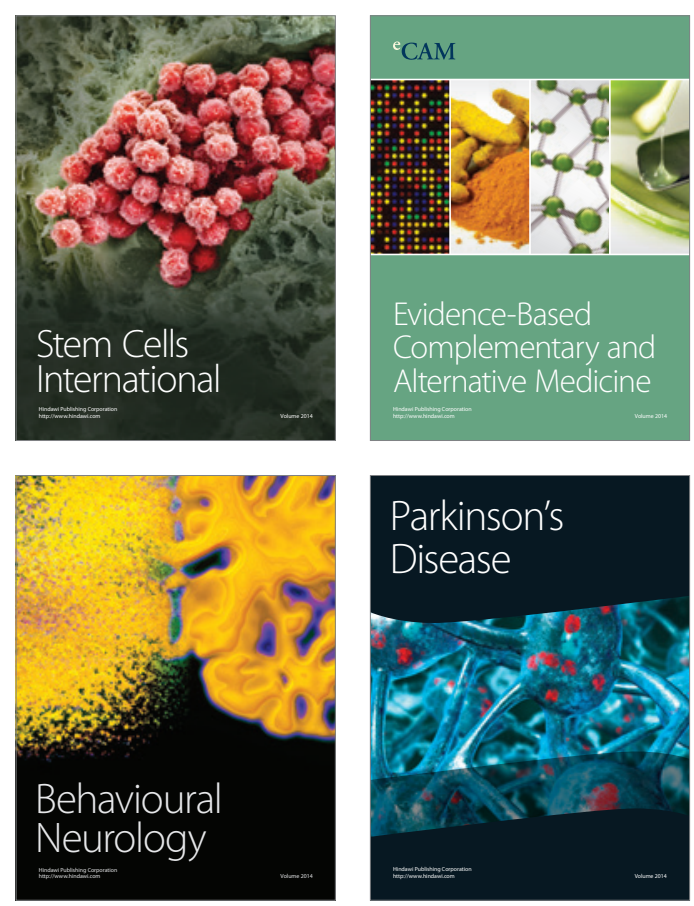

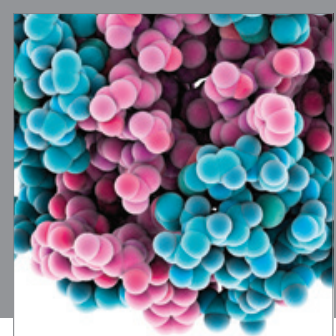

Journal of
Diabetes Research

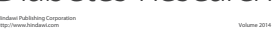

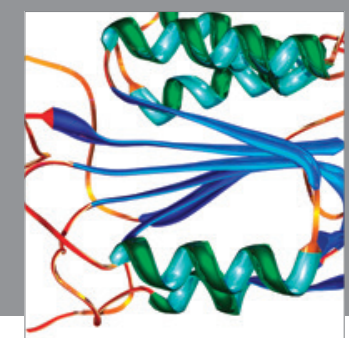

Disease Markers
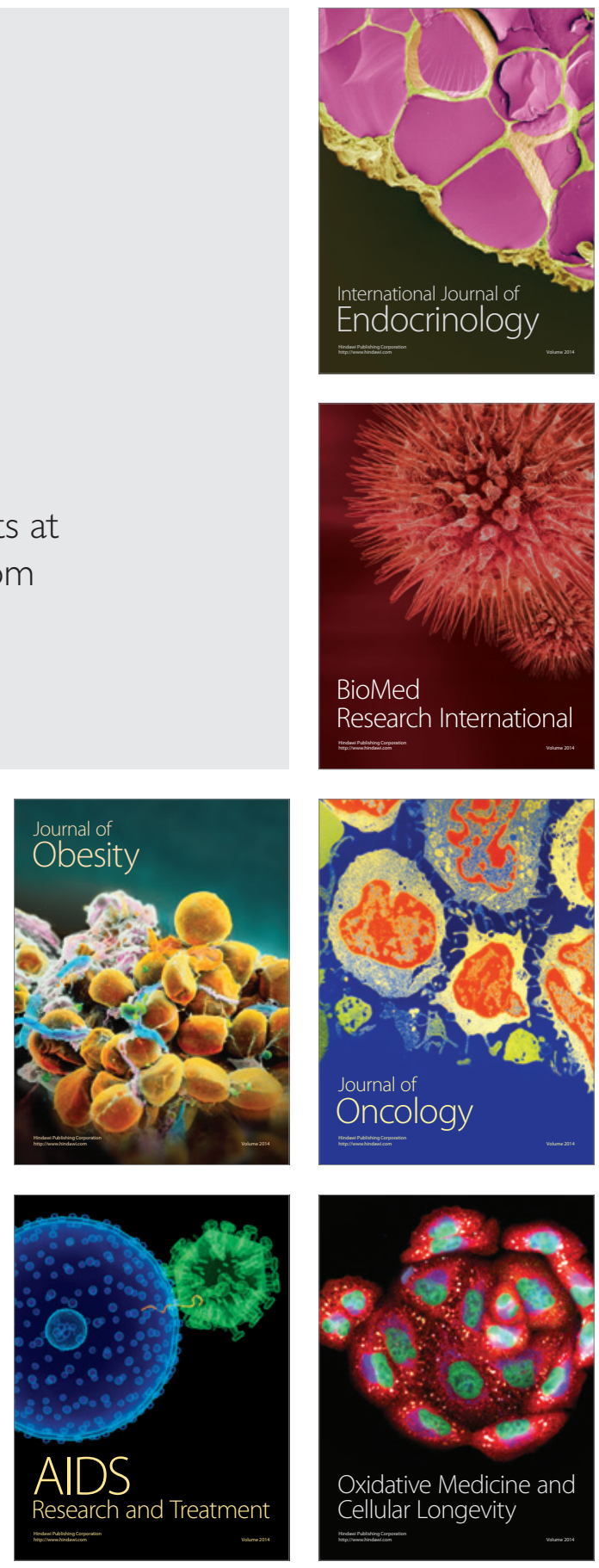